\title{
Penggunaan Metode Pose to Pose dalam Pembuatan Animasi 3D Tarian Minahasa Maengket
}

\author{
Stafira Fransisca Salmon ${ }^{1)}$, Virginia Tulenan ${ }^{2)}$, Brave A. Sugiarso ${ }^{3)}$ \\ 1,2,3 Teknik Informatika Universitas Sam Ratulangi. Manado, Indonesia \\ Email : stafirasalmonf@gmail.com ${ }^{1)}$, Virginia.tulenan@gmail.com ${ }^{2)}$, brave@ unsrat.ac.id ${ }^{3)}$
}

\begin{abstract}
Abstrak - Film Animasi 3D merupakan media hiburan yang digemari masyarakat Indonesia. Perkembangan media hiburan ini sangat berdampak pada budaya masyarakat Indonesia. Permasalahan yang sering dihadapi adalah masih kurangnya film animasi 3D dari Indonesia yang menghasilkan gerakan yang nampak realis dan tidak kaku, hal ini disebabkan karena kualitas gerakan animasi 3D. Selain itu masih kurangnya film animasi 3D menampilkan film animasi 3D tentang kebudayaan Indonesia sehingga mulai tenggelamnya budaya masyarakat karena perkembangan zaman. Untuk menghasilkan gerakan yang memiliki kualitas yang tidak kaku, pada tahap produksi animasi 3D terdapat dalam proses animating. Dalam proses tersebut perlu diperhatikan mengenai penerapan prinsip-prinsip animasi dan proses dalam penentuan dan pembentukan animasi 3D tersebut sehingga penyampaian maksud dari gerakan animasi 3D dapat dipahami oleh penonton. Dan untuk tetap melestarikan budaya Indonesia ditengah kemajuan teknologi digunakan media film animasi 3D. Pada Penelitian ini, penulis membahas tentang metode yang merupakan salah satu prinsip dalam pembuatan animasi 3D. Metode tersebut adalah metode pose to pose. Untuk penggunaan metode tersebut, penulis mengangkat salah satu kebudayaan Indonesia yaitu tarian Maengket yang diterapkan dalam animasi 3D. Dalam animasi tersebut akan ada sepasang karakter 3D memperagakan gerakan inti tarian Maengket tersebut. Perancangan penelitian ini melalui empat tahapan yaitu tahap development, tahap pra produksi, tahap produksi, dan tahap pasca produksi dengan menggunakan aplikasi Blender. Penelitian ini berhasil menerapkan metode pose to pose pada karakter 3D yang memperagakan gerakan inti tarian Maengket. Dengan pengaturan gerakan key pose, gerakan extreme dan penentuan jumlah frame pada setiap gerakan.
\end{abstract}

Kata kunci: 3D, Blender, Maengket, Pose to Pose

\section{PENDAHULUAN}

Animasi 3D merupakan salah satu media favorit masyarakat saat ini yang digunakan baik untuk hiburan, penyampaian informasi ataupun pembelajaran. Animasi 3D yang baik dipengaruhi oleh proses animating yang baik seperti pada gerakannya. Metode pose to pose merupakan salah satu metode yang digunakan dalam proses animating karena pada penerapanya metode ini mengggunakan prinsip-prinsip dasar animasi sehingga dapat membantu menghasilkan gerakan yang baik. Dalam proses animating menggunakan pose to pose, hal yang harus dilakukan adalah dengan menentukan gerakan kunci dari gerakan yang akan dianimasikan yang disebut key pose. Setelah menentukan gerakan kunci atau key pose maka selanjutnya membuat posepose di antara gerakan kunci agar gerakannya nampak lebih halus dan natural. Jika pada proses animating terdapat kesalahan pada salah satu pose nya maka dapat dengan mudah menemukan letak kesalahan animating pada pose yang ada, dan mengoreksi pose tersebut sehingga proses animating dapat berjalan dengan baik.

Kebudayaan merupakan hasil dari pikiran dan akal budi sekelompok manusia pada suatu wilayah, dimana hasil karya kebudayaan tersebut mencerminkan jati diri daerah dimana kebudayaan itu lahir. Indonesia merupakan suatu bangsa yang memiliki beragam kebudayaan baik berupa tarian, alat musik, dan lain-lain. Minahasa adalah daerah yang berada di Sulawesi Utara, Indonesia bagian tengah yang memiliki kekayaan budaya yang beragam. Salah satunya yaitu tari Maengket, dimana tari ini lahir dari kebiasaan dan keadaan lingkungan suku Minahasa pada zaman dahulu. Tari Maengket ini sangat menggambarkan suku Minahasa, namun saat ini masih banyak masyarakat Minahasa yang hanya mengenal tari Maengket ini sebatas tarian tanpa mengetahui makna dari tari Maengket tersebut. Karena itu di perlukan suatu media yang menarik untuk membantu masyarakat Minahasa dalam mengenal makna dari Tari Maengket.

Berdasarkan latar belakang tersebut penulis pose to pose dalam animasi 3D tarian Minahasa Maengket”.

\section{A. Multimedia}

Di tinjau dari bahasanya, multimedia terdiri dari 2 kata yaitu, multi dan media. Multi yang artinya banyak atau lebih dari satu sedangkan media merupakan bentukjamak dari medium, juga diartikan sebagai saran, wadah, atau alat. Istilah multimedia sendiri dapat diartikan sebagai transmisi data dan manipulasi semua 
bentuk informasi, baik berbentuk kata-kata, gambar, video, musik, angka, atau tulisan tangan dimana dalam dunia komputer, bentuk informasi tersebut diolah dari dan dalam bentuk digital. Secara umum multimedia merupakan kombinasi tiga elemen, yaitu: suara, gambar, dan teks (Mc Cormick, 1996).

\section{B. Jenis Multimedia}

\section{1). Multimedia interaktif}

Pengguna dapat mengontrol apa dan kapan elemenelemen multimedia akan dikirimkan atau ditampilkan.

\section{2). Multimedia hiperaktif}

Multimedia jenis ini mempunyai suatu struktur dari elemen-elemen terkait dengan pengguna yang dapat mengarahkannya. Dapat dikatakan bahwa multimedia jenis ini mempunyai banyak tautan (link) yang menghubungkan elemen-elemen multimedia yang ada.

\section{3) Multimedia linear}

Pengguna hanya menjadi penonton dan menikmati produk multimedia yang disajikan dari awal hingga akhir

\section{Animasi}

Animasi berasal dari kata "to animate" yang artinya menggerakan, menghidupkan. Misalnya sebuah benda yang tidak bergerak, untuk memberikan kesan hidup pada benda tersebut maka benda tersebut digerakan melalui perubahan sedikit demi sedikit. Animasi juga merupakan proses menciptakan efek gerak atau efek perubahan bentuk yang terjadi dalam beberapa waktu. Dan animasi adalah suatu teknik untuk menampilkan gambar secara berurutan sehingga adanya ilustrasi gerakan atau motion dari gambar yang ditampilkan. Dari defenisi-definisi tersebut dapat diartikan bahwa bendabenda mati dapat dihidupkan (Djalle, Zaharuddin 2007).

\section{Animasi $3 D$}

Animasi 3D merupakan animasi yang berwujud tiga dimensi meskipun bukan dalam bentuk yang sebenarnya. Didalam komputer 3D digambarkan sebagai sebuah gambar yang memiliki kedalaman (Chris Broomhall). Walaupun objek dalam animasi 3 dimensi bukan dalam bentuk objek 3D yang sebenarnya yang dapat disentuh ataupun dirasakan wujudnya namun, animasi 3D ini memiliki dimensi panjang (X), dimensi lebar (Y), dan dimensi kedalaman atau volume (Z). Pada tahap animasi 3D ini seluruh pengerjaannya mulai dari tahap modelling, texturing, lighting, hingga rendering hanya menggunakan media komputer saja.

\section{E. Timing and Spacing}

Timing and Spacing merupakan prinsip animasi.

Timing yang merupakan bagian menentukan tentang waktu kapan sebuah gerakan pada suatu objek akan di lakukan. Timing ditentukan dari jumlah frame in between yang berada di antara gerakan suatu objek atau karakter. Untuk membuat gerakan yang cepat maka jumlah frame yang digunakan semakin sedikit sedangkan untuk gerakan yang lambat diperlukan jumlah frame yang banyak. Sedangkan spacing merupakan bagian menentukan percepatan dan perlambatan sebuah objek dari bermacam-macam jenis geraknya dengan menentukan kepadatan gambarnya.

\section{F. Anticipation}

Anticipation merupakan gerakan ancang-ancang atau gerakan awal dalam mempersiapkan diri untuk melakukan gerakan selanjutnya. Contohnya seseorang yang akan melakukan gerakan tangan "maju" harus ada gerakan sebelumnya yaitu gerakan tangan "mundur" atau ancang-ancang yang akan di lakukan sesorang sebelum melompat atau berlari.

\section{G. Overlapping Action}

Overlapping action merupakan gerakan yang saling silang. Seperti gerakan kelinci melompat, sesaat setelah melompat telinganya masih bergerak walaupun gerakan utama melompat telah dilakukan.

\section{H. Metode Pose to Pose}

Metode Pose to pose adalah suatu metode yang pengerjaan animasinya dimulai dari seorang animator merencanakan keseluruhan gerakan yang akan di animasikan dan kemudian menentukan setiap keypose atau pose pose kunci dari setiap gerakan karakter tersebut. Keypose atau pose kunci sendiri merupakan kumpulan gerakan atau pose awal yang menunjukan suatu gerakan tertentu atau biasa disebut gerakan utama. Metode pose to pose ini biasanya di gunakan oleh industri animasi karena penggunaan metode ini dalam pembuatan animasi lebih cepat dan dapat memperbaiki kesalahan gerakan atau pose dengan mudah.

\section{Minahasa}

Minahasa dulunya dikenal dengan nama Malesung yang kemudian menjadi mina-esa. Mina-esa berasal dari kata asa atau esa yang artinya satu dengan awalan ma dan sisipan in yang berarti menjadi. Mina-Esa dari bahasa Tombulu artinya menjadi satu atau disatukan karena di dalamnya terdiri dari delapan sub-etnis. Dalam perkembangannya kata mina-esa menjadi minhasa yang kemudian menjadi kata Minahasa. Dan Istilah Minahasa sendiri lahir dari suatu proses kesadaran bermusyawarah antar sub-etnis untuk bersatu. (Buku Pencatatan WBTB APBNP Tari Maengket 2012 :11)

\section{J. Tari Maengket}

Tari Maengket diperkirakan sudah ada sejak abad ke-7. Pada zaman itu orang-orang Minahasa memiliki kebiasaan menyanyi sambil menari yang dipimpin oleh seseorang. Orang Minahasa pun terkenal dengan mata pencaharian bercocok tanam. Salah satu kebiasaan yang telah lama dilakukan oleh suku Minahasa dalam 
mengerjakan sesuatu seperti memetik padi dan membuat rumah dilakukan bersama-sama secara bergiliran atau dalam bentuk mapalus. Dalam aktivitas mapalus ini dikenal dengan adanya maengket. Untuk membangun semangat kerja, mereka bernyanyi sambil berbalasbalasan dan lagu yang dinyanyikan diikuti dengan gerakan sederhana. Tari Maengket adalah tarian tradisi Minahasa yang dilakukan oleh sekelompok orang yang bernyanyi sambil menari dan di pimpin oleh sesorang. Maengket berasal dari kata engket yang artinya pasang, nyalakan, buka jalan, kaitkan, dan sebagainya. Dan jika ditambahkan kata $m a$ sebagai bentuk kata kerja artinya kegiatan tarian. Kegiatan yang dimaksud seperti kegiatan yang berkaitan dengan upacara dengan tujuan menerangi, membuka jalan dan mempersatukan masyarakat pendukungnya. Dan biasanya dilakukan pada saat kegiatan panen padi (maowey), selamatan rumah baru (marambak) dan pergaulan muda-mudi (Lalayaan). (Buku Pencatatan WBTB APBNP Tari Maengket 2012 : 11)

\section{K. Blender}

Blender adalah software modelling, rendering, dan animasi 3 dimensi yang merupakan software gratis atau freeware dan terbuka atau Open source. Ukuran aplikasinya yang lebih ringan yaitu sekitar $50 \mathrm{MB}$ dan proses instalasinya yang sangat mudah membuat aplikasi ini menjadi primadona di kalangan animator Indonesia (Hendi Hendratman).

\section{Alur Pengembangan Produksi Film Animasi 3D}

Produksi film animasi 3D adalah proses yang muncul dengan melihat perencanaan groupware produksi film animasi 3D yang memiliki tahapannya. Berdasarkan Gambar 1, maka dapat dibuat film animasi 3D dengan tahapan yang dibahas selanjutnya.

\section{1) Tahap development}

Merupakan tahapan pertama dalam produksi film animasi 3D dan tahapan ini merupakan tahapan untuk mengembangkan ide cerita, dimana tahap development adalah tahap pengumpulan ide-ide yang selanjutnya ide tersebut di tuangkan dalam bentuk storyline.

\section{2) Tahap Pra Produksi}

Tahap pra produksi merupakan tahapan kedua dimana dalam tahap ini dilakukan segala persiapan yang nantinya akan digunakan dalam tahap produksi. Dan tahapan ini terdiri dari :

a. Penyususnan kru yaitu penyusunan orang-orang yang mungkin akan terlibat

b. Penyusunan Jadwal yaitu jadwal tentang hal yang akan dilakukan

c. Penyusunan anggaran yaitu kebutuhan yang diperlukan selama produksi

d. Penulisan skenario biasanya dalam bentuk dokumen tertulis tapi biasanya tahap ini dilewatkan dan langsung masuk pada tahap mengembangkan storyboard karena dengan menggunakan storyboard animator dapat memvisualisasikan filmnya. Skenario yang dibuatpun dapat berupa garis-garis besar peradegannya.

e. Pembuatan concept art yaitu proses membuat atau menggambarkan model karakter atau objek yang nantinya akan diterapkan dalam suatu aplikasi 3D.

f. Pembuatan storyboard yaitu menuangkan ide dalam bentuk gambar per adegannya sehingga dapat semakin memperjelas kebutuhan modelling dan storyboard ini dapat diubah.

g. Pemilihan pengisi suara yaitu memilih orangorang yang akan menjadi pengisi suara

h. Perekaman diaolog yaitu orang yang telah dipilih mengisi suara mereka dengan menggunakan dialog yang ada.

i. Pemodelan yaitu Proses ini dilakukan menggunakan objek 3D.

j. Rigging yaitu karakter yang tadinya telah selesai dimodelkan lewat aplikasi 3D dan disiapkan untuk dianimasikan. Didalam rigging ini karakter yang telah dimodelkan akan ditambahkan suatu rangka atau skeleton dan beberapa control ke model karakter sehinggan animator dapat dengan mudah memanipulasi gerakan atau menganimasikan karakter tersebut.

k. Pembuatan musik dan efek suara yaitu animator membuat atau menetukan jenis musik dan efek suara yang akan digunakan.

1. Pembuatan gambar in between yaitu membuat gambar gerakan suatu karakter atau objek di antara gerakan kunci atau keypose.

m. Pembuatan animatic yaitu Proses versi film dari storyboard terdiri dari gambar diam (stiil image) dengan dialog dan musik. Setelah storyboard dan diaolog selesai, maka dilakukan leica reel, yang disebut juga sebagai animatic. Leica reel terdiri dari gambar-gambar diam yang dilengkapi dengan dialog dan musik sesuai alur cerita. Leica reel yang telah selesai di "render" berfungsi untuk menunjukan berapa lama tiap shot dalam film akan dimainkan sehingga menunjukkan durasi penayangan film tersebut.

n. Teksturing yaitu menambah tekstur dan warna pada animasi agar terlihat lebih menarik.

\section{3) Tahap Produksi}

Tahap Produksi yaitu tahap pembuatan film animasi yang terdiri dari beberapa jenis bagian yaitu :

a. Animasi gerak karakter.

b. Animasi lip sync dan ekspresi.

c. Animasi setting/ latar belakang (backround).

d. Animasi efek visual spesial

e. Animasi kamera

f. Animasi pencahayaan (lighting) 
Animasi adalah seni berbasis gerakan (motion based art), dimana suatu pemahaman tentang cara bergerak objek adalah sangat penting untuk menjadi seorang animator yang andal. Salah satu dasar pentahapan proses menganimasi karakter adalah menganimasi sikap/gerakan yang keras (strong pose).

\section{4) Tahap Pasca Produksi}

Tahap Pasca Produksi merupakan tahap mengedit, memoles, dan merender animasi yang telah dibuat sehingga menghasilkan master film yang siap dikemas dalam tahapan selanjutnya. Setelah di animasi di render yang dilakukan adalah menambahkan efek-efek suara atau mensinkrokan dengan dialog.

\section{METODOLOGI PERANCANGAN}

\section{A. Analisis Kebutuhan Sistem}

Spesifikasi perangkat keras yang digunakan dalam Pembuatan Animasi 3D Tarian Maengket yaitu, sebagai berikut:
a. Processor Intel CORE i5
b. Graphic Card NVIDIA Geforce $920 \mathrm{M}$
c. RAM 4 GB
d. Hard Disk 500 GB

Sedangkan Spesifikasi Perangkat Lunak yang digubakan dalam pembuatan Animasi 3D Tarian Maengket yaitu, sebagai berikut:
a. Sistem Operasi Windows 10 pro 64 bit
b. Blender V2.68
c. Makehuman
d. Corel Video Studio Pro X6

\section{B. Tahap Development}

Dalam tahap ini, pembuatan animasi 3D Tarian Minahasa Maengket dimulai dengan penentuan ide. Ide

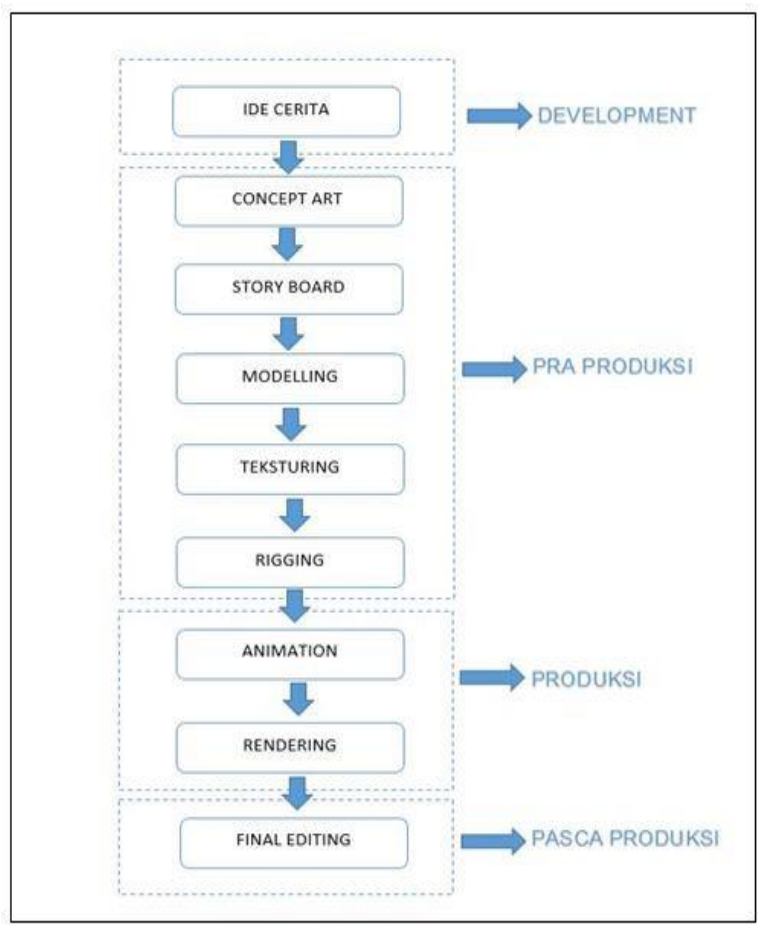

Gambar 1 Alur pengembangan pembuatan animasi 3D yang melatar belakangi penelitian ini yaitu: masih banyak pembuatan animasi 3D yang gerakannya nampak kaku, kemajuan teknologi membuat kebudayaan di Indonesia mulai luntur, Film animasi 3D menjadi media favorit masyarakat Indonesia, dan Tarian Maengket memiliki makna kebudayaan masyarakat Minahasa yang patut dilestarikan.

\section{Tahap Pra Produksi}

Tahap Pra produksi adalah tahap dimana semua kebutuhan untuk produksi disiapkan, pada tahap ini kebutuhan disesuaikan dengan proyek yang dikerjakan, Kebutuhan tahapan tersebut adalah pembuatan Concept Art membuat sketsa karakter manusia dan objek rumah adat Minahasa yang dapat dilihat pada gambar 2 dan gambar 3 .

Pada Storyboard digambarkan gerakan kunci atau key pose, gerakan extreme dan gerakan in between. Gerakan yang dibuat terdiri dari 22 scene yang didalamnya terdapat 3 babak tarian Maengket yang dapat di lihat pada gambar 4 .

Selanjutnya karakter pada sketsa di Modelling menjadi gambar 3D. Modelling karakter Laki-laki dan Perempuan awalnya menggunakan aplikasi makehuman untuk modelling usia, tinggi, warna kulit, dan gender yang kemudian karakter tersebut di import ke Aplikasi Blender untuk di modelling kembali baju dan tubuh karakter atau objek. Yang dapat dilihat pada gambar 5 . Sedangkan untuk objek rumah adat Minahasa pada gambar 6 dimodelkan menggunakan cube, plane dan mess pada icon add.

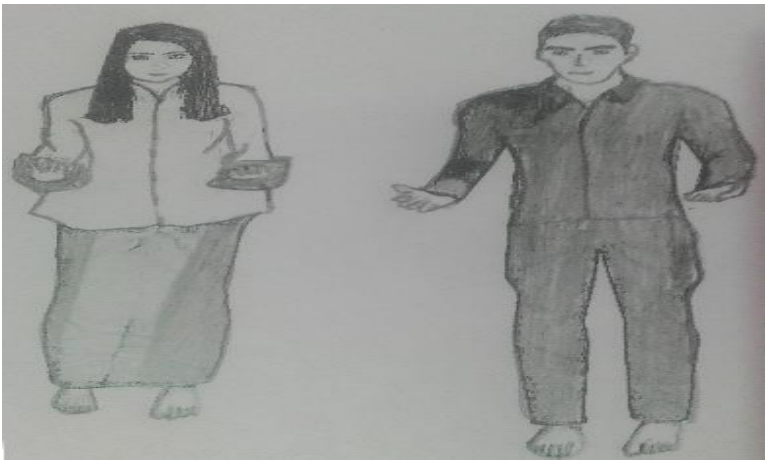

Gambar 2 Sketsa Karakter Manusia

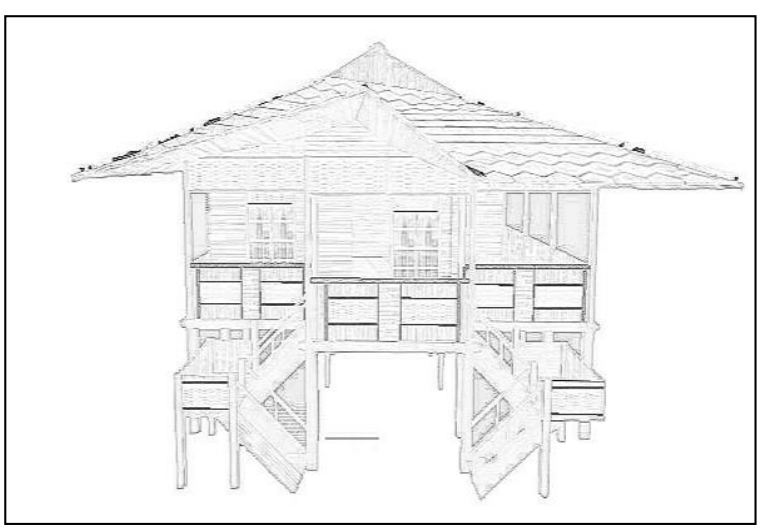

Gambar 3 Sketsa Rumah Adat Minahasa 
Karakter yang telah dimodelkan ditambahkan tulang atau biasa disebut rigging agar karakter tersebut nantinya dapat digerakkan. Proses rigging pada animasi 3D ini dilakukan pada saat karakter di modelling pada makehuman seperti pada gambar 7, kemudian diberi tekstur agar tampilan karakter dan objek lebih menarik. Penambahan tekstur dilakukan pada node editor dan $U V /$ Image editor yang kemudian di unwarp, scale dan grab untuk menyesuaikan letak tekstur yang digunakan seperti pada gambar 8 .

\section{Tahap Produksi}

Pada tahap produksi karakter yang telah dikonsepkan dan dimodelkan akan masuk pada tahap penerapan Metode Pose to Pose. Dimana Karakter tersebut akan di atur gerakannya sesuai dengan storyboard yang dibuat sebelumnya. Animation yang dikerjakan pada tahapan ini adalah dengan menentukan gerakan kunci atau key pose, gerakan extreme, dan gerakan in between. Dalam proses animation digunakan beberapa prinsip dasar animasi seperti timing and spacing, anticipation, dan overlapping action.

Pada gambar 9 merupakan pose yang nanti akan diatur menggunakan controller pada setiap tulang karakter yang akan di atur menggunakan rotate dan grab.

Gambar 10 merupakan gambar yang menampilkan gerakan-gerakan kunci. Gerak ini kemudian menjadi patokan dalam pembuatan animasi. Untuk mengatur key pose di perlukan pengaturan frame yang baik. Semakin banyak frame yang digunakan akan menghasilkan gerakan yang lambat sedangkan semakin sedikit frame yang kita gunakan gerakan yang dihasilkan semakin cepat.

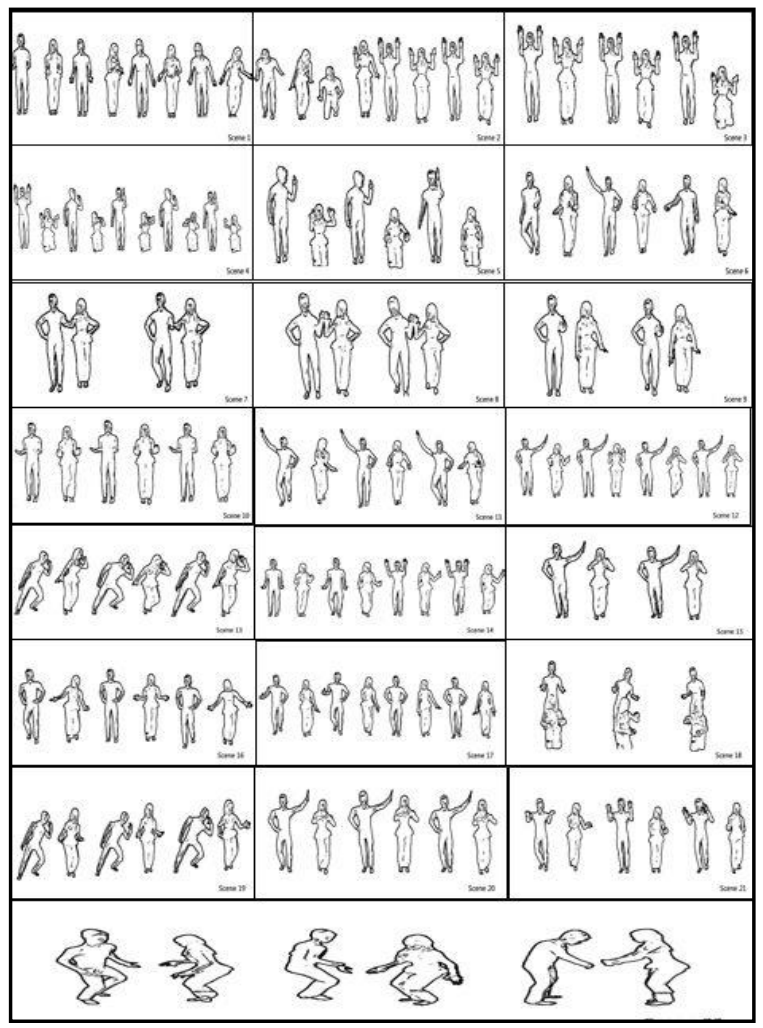

Gambar 4 Storyboard tarian Maengket
Setelah menentukan key pose, selanjutnya menentukan gerakan tambahan yang berada di antara key pose yaitu gerakan extreme seperti pada gambar 11 . Sedangkan pada Gambar 12 merupakan gerakan in between, gerakan yang lebih memperhalus animasi 3D agar gerakan bisa tampak natural dan tidak kaku.

Untuk menambah kecerahan animasi 3D tarian Maengket ini, di aturlah pencahayaan atau disebut Lighting . Dalam pencahayaan animasi 3D ini tidak menggunakan objek lamp, tetapi menggunakan pro lighting skies pada addons lightning sky dengan sky category yaitu all skies dengan pengaturan sun 0.800, Sky 1.000 dan Rotation 63 derajat. Pada Background quality menggunakan medium dengan horizon level 0.15. Pengaturan kontras kecerahan cahaya dan posisinya dilakukan untuk menghasilkan kesan pencahayaan yang lebih cerah dan terlihat nyata seperti yang terdapat pada gambar 13 .

Camera Operation atau pengambilan sudut gambar dalam animasi 3D tarian Maengket ini di ambil dari sudut depan dan sisi kiri agar dapat membantu pemahaman maksud dari gerakan yang ditampilkan seperti pada gambar 14 .

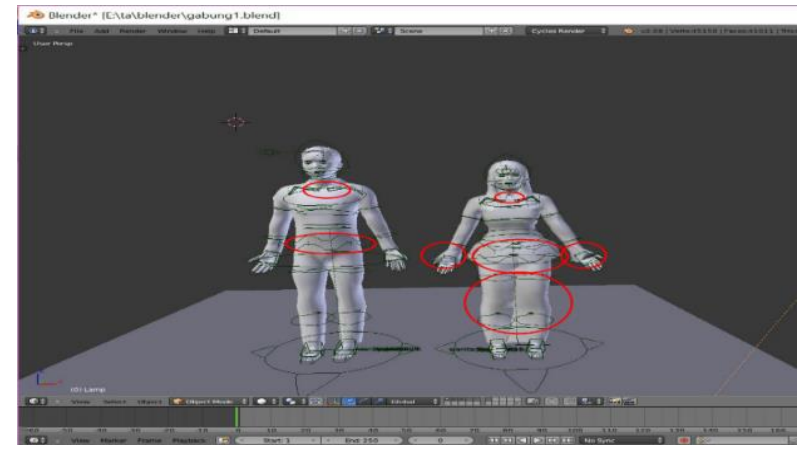

Gambar 5 Modelling karakter manusia

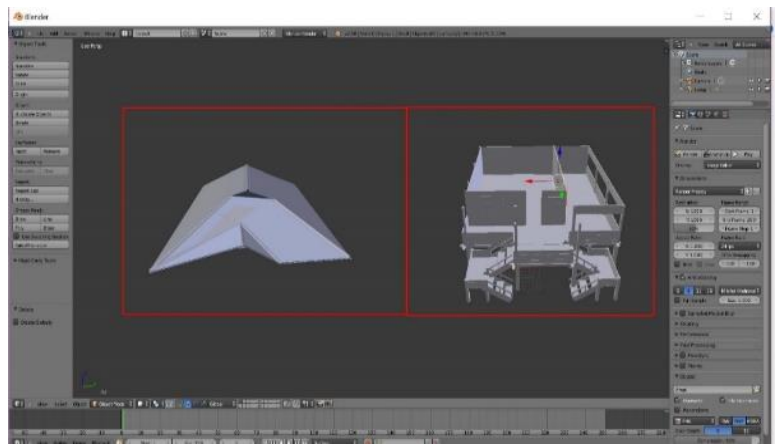

Gambar 6 Modelling objek rumah adat Minahasa

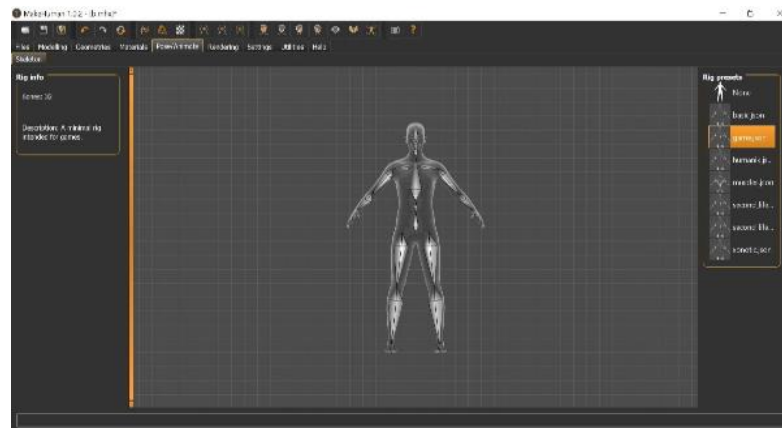

Gambar 7 Proses Rigging karakter manusia 
Objek atau karakter yang telah dimodelkan dan diatur tampilan dan gerakannya kemudian di Render didalam aplikasi blender.

Gerakan yang telah diatur kemudian dirender menjadi gambar per frame yang selanjutnya di render kembali menjadi sebuah video. Terdapat 3 jenis proses untuk merender suatu animasi yaitu render engine, blender game, dan cycles render. Proses yang mendukung gerakan pembuatan animasi tarian ini adalah dengan menggunakan cycles render karena hasil pencitraan cahayanya lebih baik.

\section{E. Tahap Pasca Produksi}

Tahapan ini merupakan tahapan yang terakhir dalam membuat video animasi 3D tarian Maengket. Pada tahap ini dilakukan Final editing menggunakan aplikasi Corel Vidio studio Pro X6. Vidio yang di edit adalah video animasi tarian Maengket dan video gerakan tarian Maengket. Final Editing ini untuk melihat perbandingan gerakan tariannya. Vidio disusun secara berurutan berdasarkan pedoman gerakan pada video manusia dan storyboard yang dibuat Final editing. Gambar 15 merupakan tampilan hasil video pada tahapan final editing.

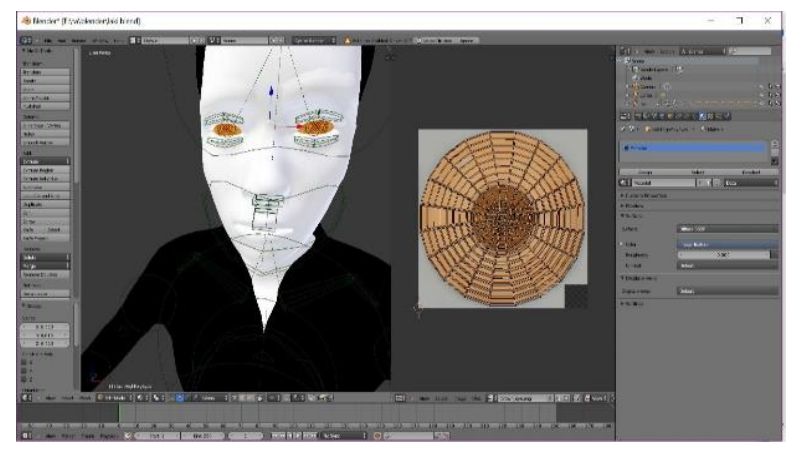

Gambar 8 Proses Tekstruing

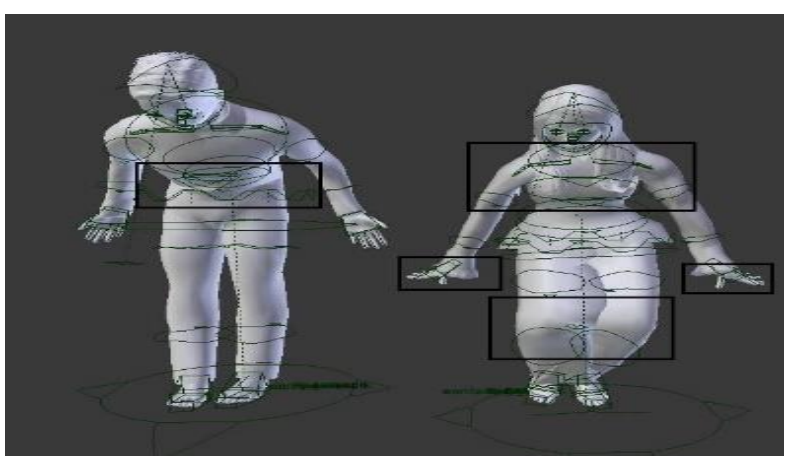

Gambar 9 Pengaturan pose

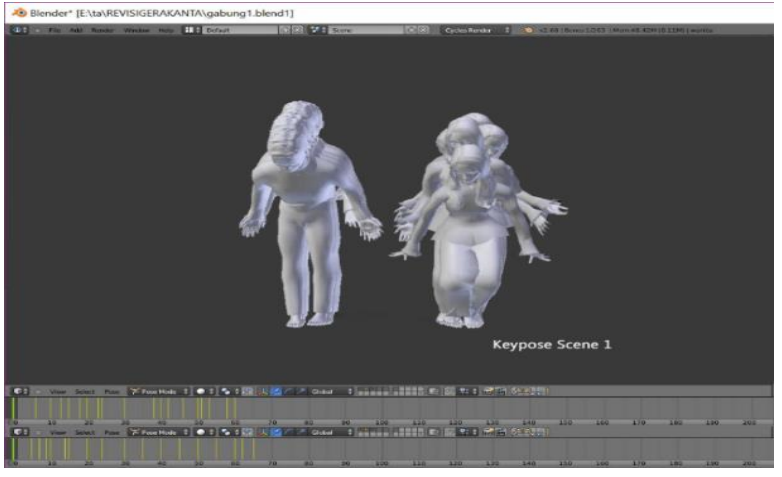

Gambar 10 Penentuan gerakan key pose

\section{HASIL DAN PEMBAHASAN}

\section{A. Hasil Pengamatan}

Berdasarkan Hasil Pengamatan pada Penelitian “ Penggunaan Metode Pose to Pose dalam Animasi 3D Tarian Minahasa Maengket" untuk membuat suatu gerakan yang nampak realis dan tidak kaku, penulis menentukan gerakan kunci atau key pose terlebih dahulu. Selanjutnya dalam membuat gerakan juga di perlukan pengaturan Frame yang baik. Seperti untuk membuat gerakan dengan durasi cepat penulis menggunakan frame dengan jumlah antara 10-25, sedangkan untuk membuat gerakan yang lambat penulis menggunakan frame dengan jumlah antar 40-60. Selain itu penentuan extreme juga sangat berpengaruh. Penulis menentukan extreme pada gerakan yang memiliki gerakan tambahan dengan jarak 3 sampai 5 frame untuk perubahan gerakan yang berbedah jauh dari gerakan sebelumnya, sedangkan untuk perubahan gerakan yang tidak terlalu berbeda dengan gerakan sebelumnya penulis menggunakan frame dengan jarak 1 frame.

\section{B. Hasil Pengelolaan}

Hasil pada tahap Pra Produksi penulis mengkonsepkan animasi yang akan dibuat. Seperti penulis membuat sketsa karakter dan benda yang akan dibuat, membuat storyboard dengan jumlah 22 Scene sesuai dengan video tarian yang digunakan sebagai acuan pembuatan animasi 3 dimensi tarian Minahasa Maengket dan dapat dilihat pada gambar 16.

Selanjutnya pada tahapan produksi penulis menerapkan metode pose to pose pada proses animation. Pada tahapan ini story board yang telah dibuat diterapkan menggunakan aplikasi Blender.

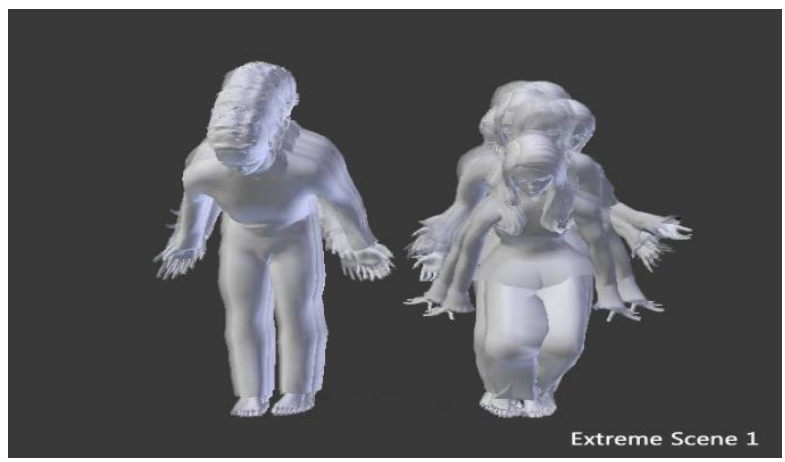

Gambar 11 Penentuan gerakan extreme

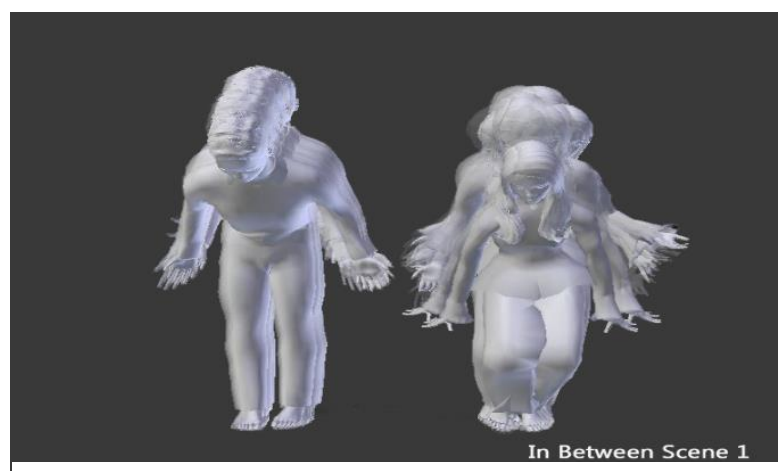

Gambar 12 Gerakan in Between 
Ditahap ini gerakan-gerakan yang dihasilkan karakter diatur menggunakan tools Grab dan rotate pada setiap controller yang ada pada karakter tersebut. Gambar 17 hasil dari tahapan pra produksi.

Dan tahapan terakhir yang dilakukan adalah Tahapan Pasca Produksi. Pada tahapan ini animasi yang telah dibuat di edit oleh penulis untuk dijadikan dijadikan video animasi. Yang kemudian di satukan dengan video tarian maengket yang diperagakan oleh Wulan Waraney Minahasa sebagai perbandingan tentang penggunaan metode pose to pose dalam pembuatan animasi 3D tarian Maengket Minahasa yang dapat menghasilkan gerakan yang Nampak realis dan natural. Vidio animasi 3D yang dihasilkan ini berdurasi 2 menit 44 detik dengan menampilkan perbandingan gerakan serta makna dari gerakan tersebut.

Dan tahapan terakhir yang dilakukan adalah Tahapan Pasca Produksi. Pada tahapan ini animasi yang telah dibuat di edit oleh penulis untuk dijadikan dijadikan video animasi. Yang kemudian di satukan dengan video tarian maengket yang diperagakan oleh Wulan Waraney Minahasa sebagai perbandingan tentang penggunaan metode pose to pose dalam pembuatan animasi 3D tarian Maengket Minahasa yang dapat menghasilkan gerakan yang Nampak realis dan natural. Vidio animasi 3D yang dihasilkan ini berdurasi 2 menit 44 detik dengan menampilkan perbandingan gerakan serta makna dari gerakan tersebut.

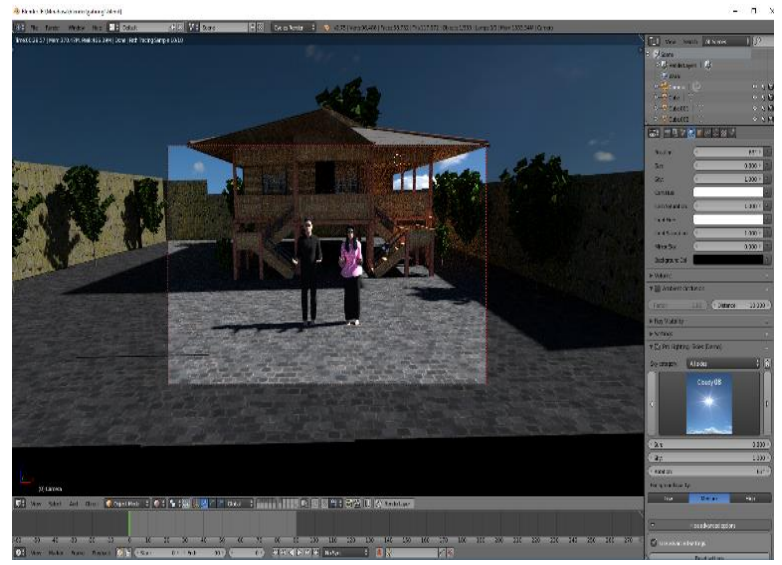

Gambar 13 Tampilan hasil pencahayaan

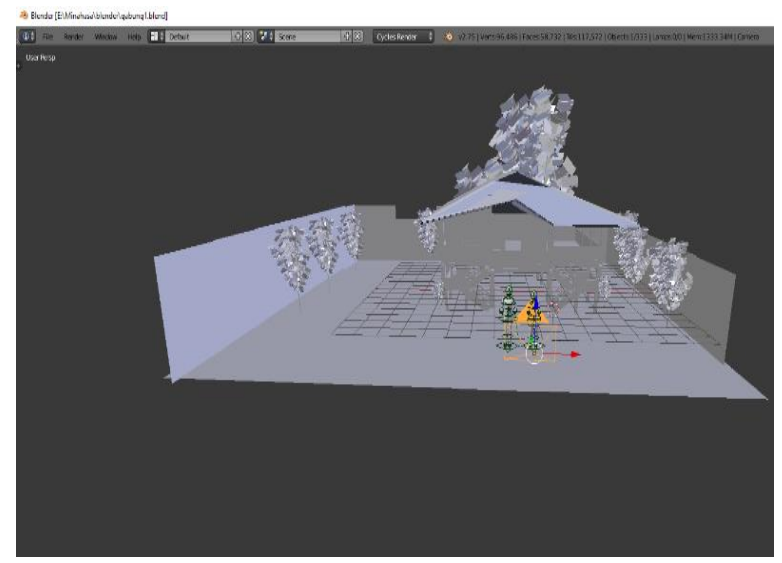

Gambar 14 Pengaturan sudut pengambilan gambar
C. Hasil Pembahasan

Berdasarkan pada penelitian "Penggunaan Metode Pose to Pose dalam Animasi 3D Tarian Minahasa Maengket", jenis multimedia yang diterapkan adalah Multimedia Linear karena pada video animasi 3 dimensi ini pengguna menjadi penonton dan menikmati produk multimedia yaitu animasi 3 dimensi yang disajikan dari awal. Dan adapun prinsip-prinsip animasi yang diterapkan pada video animasi 3 dimensi tarian minahasa Maengket yaitu :

1) Timing dan Spacing

Prinsip ini menentukan waktu dan kecepatan untuk gerakan badan khususnya gerakan tangan dan kaki. Penentuan ini dilihat dari frame in between yang berada di antara gerakan karakter. Gambar 18 merupakan salah satu penerapan prinsip Timing dan Spacing.

\section{2) Anticipation}

Gerakan ancang-ancang yang sebelum melakukan gerakan utamanya. Penerapan anticipation pada penelitian ini adalah gerakan ayunan tangan kebelakang sebelum diangkat kedepan seperti gambar 19.

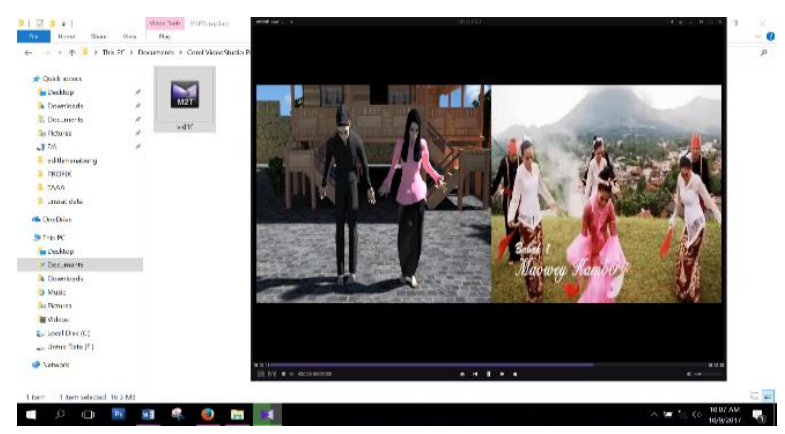

Gambar 15 Hasil video Final editing

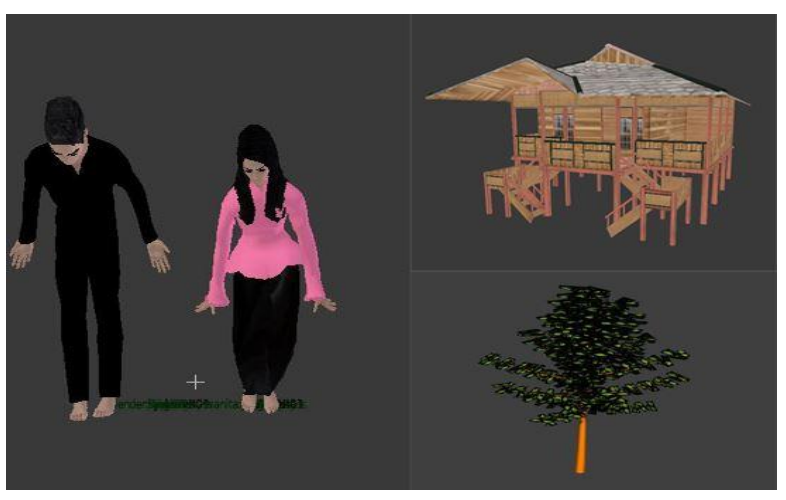

Gambar 16 Hasil tahapan Pra Produksi

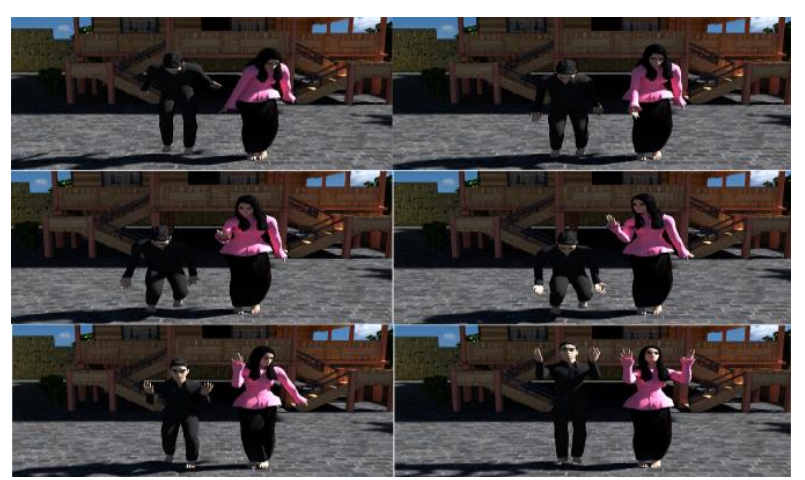

Gambar 17 Hasil tahapan produksi 


\section{3) Overlapping Action}

Gerakan diantara gerakan utama pada animasi ini diterapkan seperti pada gerakan kedipan mata, bernafas dan gerakan tangan. Prinsip ini selalu diterapkan pada setiap scene animasi 3 dimensi tarian Maengket agar gerakan tidak kelihatan kaku seperti gambar 20.

\section{4) Metode pose to pose}

Langkah awal yang dilakukan dengan keypose dari karakter dan kemudian gerakan extreme serta gerakan in between. Dengan menggunakan metode ini gerakan yang dihasilkan nampak natural dan jika terjadi kesalahan dalam suatu gerakan dapat dengan mudah diperbaiki karena telah mengetahui gerakan kunci animasi.

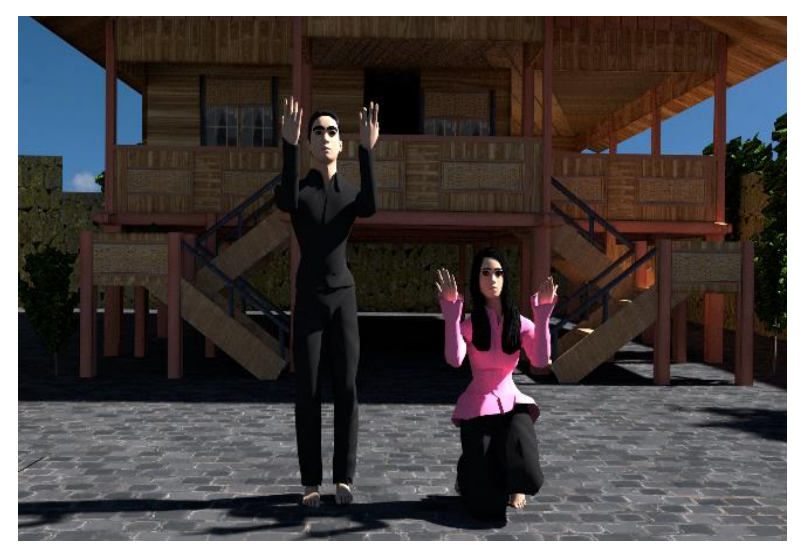

Gambar 18 Hasil Penerapan Timing and Spacing

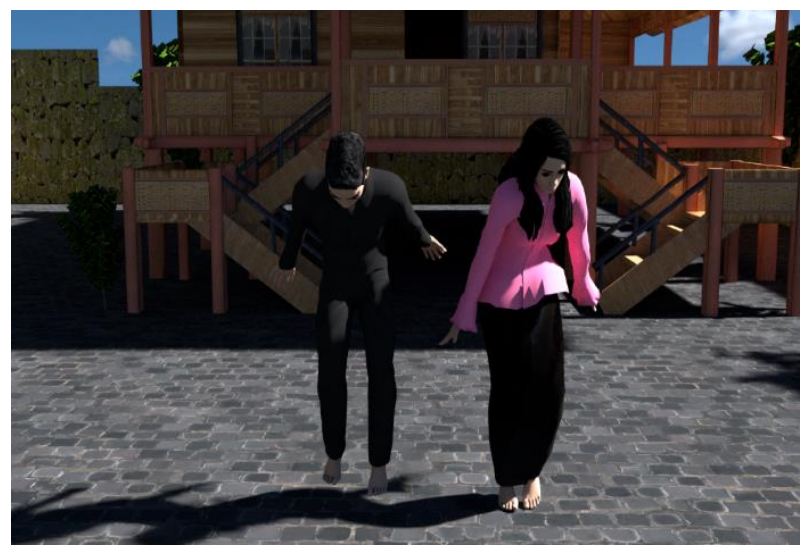

Gambar 19 Penerapan Anticipation

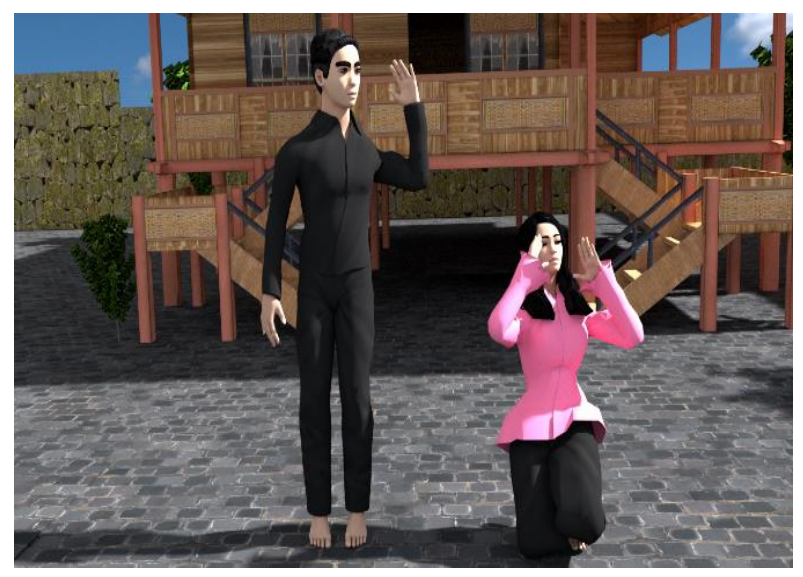

Gambar 20 Penerapan Overlapping Action
Tabel 1 merupakan tabel yang menjelaskan penggunaan Metode pose to pose tentang jumlah keypose dan extreme yang digunakan pada setiap scene untuk menghasilakan gerakan yang realis dan Nampak natural.

\section{PENUTUP}

\section{A. Kesimpulan}

Berdasarkan penelitian tentang Penggunaan Metode Pose to pose dalam animasi 3D Tarian Minahasa Maengket, maka kesimpulan yang didapatkan pada penelitian ini yaitu:

1) Semakin banyak frame yang gunakan dalam pembuatan animasi 3 dimensi maka gerakan animasi yang dihasilkan akan semakin nampak realis dan tidak kaku.

2) Penyesuaian penggunaan jumlah frame sangat penting, untuk menghasilkan gerakan yang cepat sebaiknya menggunakan 10-25 frame sedangkan untuk menghasilkan gerakan yang lambat sebaiknya menggunakan 40-60 frame.

3) Pengaturan gerakan extreme yang digunakan haruslah sesuai dengan kebutuhan gerakan agar gerakan yang dihasilkan nampak natural.

4) Metode pose to pose telah berhasil diterapkan pada pembuatan animasi 3 dimensi Tarian Minahasa Maengket dan menghasilkan gerakan manusia dengan kualitas gerak animasi yang nampak realis.

TABEL 1 Hasil Pengelolaan Data

\begin{tabular}{|c|c|c|c|}
\hline \multirow{2}{*}{ Scene } & \multicolumn{3}{|c|}{ Jumlah } \\
\hline & Keypose & Extreme & Frame \\
\hline Scene 1 & 7 & 11 & 65 \\
\hline Scene 2 & 6 & 20 & 140 \\
\hline Scene 3 & 3 & 9 & 65 \\
\hline Scene 4 & 9 & 28 & 120 \\
\hline Scene 5 & 5 & 24 & 120 \\
\hline Scene 6 & 4 & 14 & 35 \\
\hline Scene 7 & 7 & 6 & 30 \\
\hline Scene 8 & 7 & 5 & 30 \\
\hline Scene 9 & 7 & 7 & 30 \\
\hline Scene 10 & 9 & 9 & 40 \\
\hline Scene 11 & 7 & 9 & 60 \\
\hline Scene 12 & 13 & 10 & 85 \\
\hline Scene 13 & 5 & 13 & 60 \\
\hline Scene 14 & 10 & 10 & 60 \\
\hline Scene 15 & 4 & 8 & 20 \\
\hline Scene 16 & 7 & 12 & 60 \\
\hline Scene 17 & 7 & 14 & 70 \\
\hline Scene 18 & 6 & 8 & 45 \\
\hline Scene 19 & 11 & 8 & 60 \\
\hline Scene 20 & 9 & 6 & 40 \\
\hline Scene 21 & 7 & 6 & 30 \\
\hline Scene 22 & 7 & 7 & 60 \\
\hline
\end{tabular}




\section{B. Saran}

Adapun beberapa saran dari peneliti :

1) Dalam pembuatan animasi 3 dimensi untuk penggunaan komputer sebaiknya dengan spesifikasi yang mendukung proses pembuatan animasi agar menghasilkan animasi yang lebih baik dan tidak mengalami kendala dalam proses pembuatannya.

2) Metode pose to pose dapat diterapkan pada pembuatan animasi-animasi umumnya sehingga gerakan yang dihasilkan tidak kaku.

3) Dalam pembuatan animasi 3 dimensi penggunaan extreme harus berdasarkan kebutuhan gerakan animasi yang akan dibuat.

\section{DAFTAR PUSTAKA}

[1] Buku Pencatatan WBTB APBNP, 2012, Tari Maengket

[2] D.Sari, Desember 2012, Perencanaan Kebutuhan Pengguna Pada Produksi Film Animasi Tiga Dimensi Untuk Pengembangan Groupware, Jurnal IPTEKKOM,Vol. 14, No. 2

[3] Erika D. Indraswari, 2012, Kiat Belajar Gerak Karakter Animasi, Jurnal Humaniora, Vol. 3, No. 2

[4] Ivan R. B. Kaunang, 2015, Kemasan Tari Maengket Dalam Menunjang Industri Kreatif Minahasa Sulawesi Utara Di Era Globalisasi. Jurnal LPPM, Vol. 2, No. 1.

[5] Leonardi Yudistira. Rotinsulu, 2015, Animasi 3D Sosialisasi Penanganan Rabies Pada Masyarakat Dengan Waterfall Yang Disederhanakan, e-journal Teknik Elektro dan Komputer, Volume 4, No. 4

[6] Make Human (Definisi Make Human), tersedia di: http//www.makehuman.org, diakses pada tanggal jumat 24 maret 2017

[7] Munir, 2012, Multimedia Konsep dan Aplikasi dalam Pendidika, Alfabeta, Bandung

[8] Victor Waeo, 2016, ImplementasiGerakan Manusia pada Animasi 3D dengan menggunakan Metode Pose to Pose, Jurnal Teknik Informatika, Vol. 9, No.1.

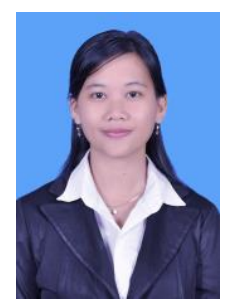

\section{TENTANG PENULIS}

\section{Stafira Fransisca Salmon,}

lahir di Tondano pada tanggal 5

September 1994. Penulis menempuh Pendidikan secara berturut-turut di TK

Santu Mikael Airmadidi (1999-2000), SDN Inpres Tondano (2000-2006), SMP Negeri 1 Tondano (20062009), dan lulus dari SMA Negeri 1 Tondano (20092012).

Pada tahun 2013, penulis melanjutkan studi di Program Studi Informatika, Jurusan Teknik Elektro, Fakultas Teknik, Universitas Sam Ratulangi. Selama masa kuliah, penulis telah menjalani kerja praktek di Badan Kepegawaian Daerah Prov.Sulut, serta
Kapataran, Kecamatan Lembean, Kabupaten Minahasa. Selama kuliah penulis pernah tergabung dalam organisasi kemahasiswaan yaitu, UPK-Kr.FT Unsrat dan Himpunan Mahasiswa Elektro FT-Unsrat. Penulis menyelesaikan studi di Program Studi Informatika, Jurusan Teknik Elektro, Fakultas Teknik, Universitas Sam Ratulangi pada 10 Oktober 2017. 